\title{
Interaction Design as a Bricolage Practice
}

\author{
Anna Vallgårda \\ IxD lab \\ IT University of Copenhagen \\ Copenhagen, Denmark \\ akav@iu.dk
}

\author{
Ylva Fernaeus \\ Dept. of Media Technology and Interaction Design \\ Mobile Life Centre and KTH \\ Stockholm, Sweden \\ fernaeus@kth.se
}

\begin{abstract}
With this paper we propose bricolage as an interaction design practice. We make the case that bricolage promotes design qualities that are specifically tuned to tangible and material computing practices in that it is highly sensible towards the unstable physical world and proposes a nonhierarchical negotiation of forms. We further show how bricolage can aid design results with strong and rich cultural and material grounding. Finally, we argue how bricolage and mythical thinking can be proponents for new ways of thinking and using technology.
\end{abstract}

\section{Author Keywords}

Bricolage; mythical thinking; design practice; interaction design; tangible computing; material computing;

\section{ACM Classification Keywords}

H.5.m. Information interfaces and presentation (e.g., HCI): Miscellaneous.

\section{INTRODUCTION}

Conceptual design plays an important role in pivoting research in interaction design forward [27]. It changes how we see the potential of the technology and thus what we will do with it. In this paper, however, we will look at their polar opposite - the bricolage - and analyze how this practice of making can bring forward an alternative path expanding how we see and use technology. Bricolage is, as we will develop further in the paper, a way of making which draws on what is already there both culturally and materially. It is a practice that favors making connections between the tools and materials at hand rather than looking for globally optimal solutions. Bricolage is an everyday concept in many Roman languages and denotes a builder or a tinker. In this paper, however, we rely on the more elaborate description provided by the anthropologist LéviStrauss [17]. We find his notion of bricolage and mythical thinking offers a fundamentally different way of making compared to conceptual design.

Permission to make digital or hard copies of all or part of this work for personal or classroom use is granted without fee provided that copies are not made or distributed for profit or commercial advantage and that copies bear this notice and the full citation on the first page. Copyrights for components of this work owned by others than ACM must be honored. Abstracting with credit is permitted. To copy otherwise, or republish, to post on servers or to redistribute to lists, requires prior specific permission and/or a fee. Request permissions from permissions@acm.org. TEI '15, January 15-19, 2015, Stanford, California, USA.

Copyright is held by the owner/author(s). Publication rights licensed to ACM. ACM 978-1-4503-3305-4/15/01 ..\$15.00.

http://dx.doi.org/10.1145/2677199.2680594
Bricolage, in the notion from Lévi-Strauss, has previously been introduced to design thinking most notably by Louridas [18] who proposes to use bricolage as a metaphor to describe all design practice. His purpose is to draw out and discuss the relationship between design and art and design and science. Several interaction design researchers $[10 ; 12 ; 14 ; 30 ; 34]$ also touch upon the notion most often, however, using Louridas' interpretation [18] in which design work per se is considered a bricolage practice. Our aim here is to look at bricolage as a particular way of practicing design - a way distinguished from that of engineering and conceptual design.

Indeed, the reason why we find bricolage a both suitable and interesting practice for interaction design, especially when working with tangible and material computing, is fourfold. First of all, the bricoleur is not curbed by the impreciseness of our physical world rather she will use it to her advantage. When working solely with graphical user interfaces we are rarely toppled by any imperfections or unpredictable events in our technology - it tends to behave as prescribed. Breaking out into the varied multitude of input and output devises, as we do in tangible and material computing, we constantly meet those imperfections. Instead of dismissing these quirks as just bumps in the road in an early prototype and polish the conceptual description, bricolage proposes to work with them - to exploit them.

Second, the bricoleur does not plan ahead but develops the project in-situ with concerns of interaction, physical form, and behavior pattern not being hierarchically ordered $a$ priori. Thus, the bricolage is the result of careful negotiations in the making, which render it less skewed towards either (i.e. as we often see in co-design or technology driven design).

Third, we find how bricolage proposes interesting ways of creating more culturally grounded and material rich artifacts because it operates in-situ and not towards an imagined future.

And fourth, we find bricolage to provide fruitful ways of constraining the design space and that the mythical way of thinking provides promising ways of making new connections. Connections, which in turn can help open new design spaces and in general expand our understanding of technological potentials. However, there are also limitations 
to a bricolage practice, for instance, the inherently local optimal solutions and the potential conservative results.

In the first part of the paper we present a close reading of Lévi-Strauss' notions of mythical thinking and bricolage tailored to be read prescriptively. We then look at how the notion has been used in interaction design literature. Afterwards, we analyze the qualities of bricolage as a particular design practice, specifically in the context of interaction design. We go on to discuss some of the limitations of the practice. And finally, we briefly mention which areas of interaction design we believe could benefit from practicing bricolage and mythical thinking.

\section{BRICOLAGE \& MYTHICAL THOUGHT}

In his book 'The Savage Mind' [17], the anthropologist Lévi-Strauss makes the argument that 'primitive cultures' seems to develop a language for and, thus understanding of, things in their surroundings even if they find them more interesting than useful. He makes the point that for them "animals and plants are not [necessarily] known as a result of their usefulness; they are deemed to be useful or interesting because they are first of all known" [17, p. 9]. This is the cornerstone in the mythical thinking (intellectual plane) and the bricolage practice (technical plane) we will present here in the context of interaction design.

We are not about to compare the practice of interaction design to a 'primitive culture' rather Lévi-Strauss' point is that this way of thinking and making is thriving side-byside with scientific thinking and engineering even in industrial and post-industrial cultures. And our point is that there are significant qualities to be found for interaction design in this immediate way of structuring events through material assemblage and modification that together signifies the practice of bricolage.

Lévi-Strauss is a structuralist and as a general worldview we would perhaps rather argue for a post-structuralistic one. We find, however, that there is little conflict between the notions of mythical thinking and bricolage and a more poststructuralistic perspective since they are both about the constant creation and re-creation of structures based on particular events. Further, we propose them here as some sort of meta-structures we can adapt and appropriate in our practice rather than a specific method.

\section{Bricolage}

Basically, there are three crucial points to a bricolage practice, which regards what the bricoleur works with, the nature of his skill-set, and especially how he works.

\footnotetext{
${ }^{1}$ In The Savage Mind [17] mythical thought and magic is used seemingly interchangeably. We suspect this is specific to the English translation but we are not in possession of the French edition. For the sake of simplicity we only use mythical thought in this paper.
}

The bricoleur's task is to 'take to pieces and reconstruct sets of events (on a physical, socio-historical or technical plane) and use them as so many indestructible pieces for structural patterns in which they serve alternatively as ends or means" [17, p. 33]. In other words, it is to make a structure of events. These events may be prior to the project and as such even occasion it. They may be intrinsic to "the course of execution itself, in the size or shape of the piece of wood" [17, p. 27]. Lastly, they may be posterior to the act of creation. For example, when the work is created to an end the bricoleur will consciously or unconsciously put himself "in the place of the person for whose use it is intended" [17, p. 27]. Thus, the bricoleur may start out with an idea of a project but the result will always be a compromise between what is already there and what is needed. "His universe of instruments is closed and the rules of his game are always to make "whatever is at hand" " [17, p. 17]. Indeed, the bricoleur's treasury of materials and tools does not pertain to neither the current project nor any prior particular project but are the "contingent result of all the occasions there have been to renew or enrich the stock or to maintain it with the remains of previous constructions or deconstructions" [17, p. 17].

Second, the bricoleur does not "need the equipment and knowledge of all trades and professions" [17, p. 18] but operates based on interpretations of the relation between the materials and tools before him. The 'bricoleur' is adept at performing a large number of diverse tasks; but, unlike the engineer, he does not subordinate each of them to the availability of raw materials and tools conceived and produced for the purpose of the project [17]. In other words the bricoleur sometimes uses the tools (and materials) as they were used before but he is also able to reinterpret their function in the course of the execution. Further, the bricoleur rely on his own experience - his own history of events - in everything he does.

Third, the bricoleur's task is to make structure of the events before him (his treasury). The first step of execution is thus always retrospective. "He has to turn back to an already existent set made up of tools and materials, to consider or reconsider what it contains and, finally and above all, to engage in a sort of dialogue with it and, before choosing between them, to index the possible answers which the entire set can offer to his problem. He interrogates all the heterogeneous objects of which his treasury is composed to discover what each of them could 'signify' and so contribute to the definition of a set which has yet to materialize but which will ultimately differ from the instrumental set only in the internal disposition of its parts" $[17$, p. 18]. For example, "[a] particular cube of oak could be a wedge to make up for the inadequate length of a plank of pine or it could be a pedestal - which would allow the grain and polish of the old wood to show advantage. In one case it will serve as extension, in the other as material" [17, pp. 18-19]. 
Importantly, though, the bricoleur does not start tabula rasa rather "the possibility always remain limited by the particular history of each piece and by those of its features which are already determined by the use for which it was originally intended or the modification it has undergone for other purposes" [17, p. 19].

Thus, bricolage is not merely about a reflective conversation with materials in a design situation [cf., 26]. Indeed, the reflective conversation with materials can be seen as aspects that engineering and bricolage have in common - much like the systematics of both mythical thought and science. Rather, bricolage differs by being an in situ structuring of events through material assemblage and modification - in a process with no hierarchal ordering. Where the in situ also adheres the restricting of tools and materials to whatever is at hand thus making the outcome both local and particular.

\section{Mythical thought}

Bricolage is the technical plane - the practice of making that accompanies the intellectual plane of the mythical way of thinking [17]. Thus, mythical thought can be seen as the mind-set responsible for the nature of the structure made in a bricolage.

Mythical thought makes connections between cause and effects as they appear. It is a way of thinking that connects events, not because that would give an insight, but because these events take place there "immediately presented to the senses" [17, p. 11], at the same time or right after each other. Its reasoning is systematic and arguments coherent yet the explanations and conclusions may, from a scientific perspective, seem outlandish. Indeed, the quality of myths is the poetry that arises from these alternative connections of events and sometimes even the alternative connections per se. "The elements of mythical thoughts [..] lie somewhere between percepts and concepts" [17, p. 18]. Thus, mythical explanations offer a foundation for stories, wonder, and imagination. Furthermore, the mythical thought does not discriminate in layers of knowledge as scientific thought does. Rather, it approaches everything at the same level which is why it is able to bridge events differently.

For example, in a myth that connects the touch of a woodpecker's beak and toothache, "the real question is not whether the touch of a woodpecker's beak does in fact cure toothache. It is rather whether there is a point of view from which a woodpecker's beak and a man's toothache can be seen as 'going together' (the use of this congruity for therapeutic purposes being only one of its possible uses), and whether some initial order can be introduced into the universe be means of these groupings. Classifying, as opposed to not classifying, has a value of its own, whatever form the classification may take" [17, p. 9]

"For even a heterogeneous and arbitrary classification preserves the richness and diversity of the collection of facts it makes. The decision that everything must be taken account of facilitates the creation of a "memory bank" [ $[17$, p. 16]

The point is, that "every object made by man is the embodiment of what is at once thinkable and possible" [19, p. 17] as Manzini states in the opening of his seminal book The Material of Invention. Articulating and classifying is part of the practice of making it thinkable. Doing so from a mythical perspective rather than a scientific perspective will enable us to think and, consequently, to make differently. Further, Lévi-Strauss [17] stresses how mythical thought is not merely a naive predecessor to scientific thinking rather it is a way of thinking with entirely different ways and means.

This account of bricolage is not to be interpreted as a manifesto to be followed dogmatically. It is a proposal for a way of thinking and making fundamentally different than engineering and in that we find it to hold some qualities, which we will analyze after we have looked at related work.

\section{RELATED WORK}

Panagiotis Louridas' proposal [18] of metaphorically seeing design as bricolage is probably the most influential introduction of bricolage in design thinking that also found its way to interaction design. He too draws on Lévi-Strauss notion of bricolage and uses it to analyze in what ways design differs from the practices of science and art. His errand is descriptive, as opposed to our more prescriptive, in that he uses bricolage as an analytical lens to discuss the nature of design [18]. Louridas' analysis is divided between the unselfconscious designer and the self-conscious one, which he borrows from Alexander [1]. The unselfconscious one is the original bricoleur, the craftsman, who is bound by tradition and only is allowed a limited form of originality [18]. The other is the modern designer who designs for manufacturing and uses design methods [cf., 5]. This designer has the responsibility of setting up his own scene for the bricolage - create his own treasury. $\mathrm{He}$ is responsible for determining which events that should be included in the structure [18]. What we aim to do with this paper is to propose bricolage as a particular way of practicing design for the self-conscious designer. Thus, unlike Louridas, we argue that bricolage differs from design-by-drawing, conceptual design, or engineering which are otherwise common ways of practicing selfconscious design. The differences lies primarily in its lack of outlook - its in situ nature that results in local and particular structures, construed through a mythical mindset. We acknowledge that all self-conscious design is a matter of conversation with events, and through that structuring them, but it is the scope of those events the mindset behind the structuring that distinguishes a bricolage from most modern and engineer based design.

Louridas paper has inspired others to analyze interaction design practices as bricolage. Most prominent is Wakkary and Maestri's studies of the everyday designer and thus 
what can be seen as the unselfconscious designer [34]. Through ethnographic studies in family homes they identified and analyzed the design aspect of the families microstructures.

The Tanenbaums and Wakkary [30] later uses bricolage to articulate the practice of Steampunk design and thus emphasizing the bricolage practice's quality of remaining within the cultural and aesthetic tradition of the bricoleur.

Hazelwood et al. [14] bring forward bricolage in a simplified version in which they propose to use a combination of bricolage and consultancy for the design of large-scale installations. "By bricolage we refer to the act of making resourceful use of materials that are 'at hand' and tinkering with them" [14, p. 386]. They introduce consultancy to overcome the risk of suboptimal solutions by only relying on the skills of the bricoleur.

Fallman [10] argues how bricolage is closely related to the pragmatic and hermeneutic practice of design that, for instance, Schön puts forward with his notion of reflective conversation with the materials at hand [26]. We have argued above, however, how bricolage is somewhat more than that. Indeed, we suggest that the conversation with materials rather can be seen as one of the common traits of engineering and bricolage.

Büscher et al. [4] uses bricolage as an idea for a cost effective method for situated design. Their main point is that 'designing immediately' accommodates the situatedness of a work organization and, thus, helps minimize the gap so often seen between technical solution and the actual organization of work [4]. This work is interesting in that it broadens the scope of tools and materials to also include actors. It applies bricolage to a context beyond the dull artifacts to also include interactive technologies. Indirectly, this work even suggests that bricolage could be used in a practice of the more ephemeral user experience design besides the more tangible interaction design we will discuss in this paper.

Another area related to interaction design in which bricolage has played an analytical role is in creative and end-user programming practices [3]. Especially child programming has found a prominent use of the concept [11; 25]. The main take on bricolage in this body of work is based on Turkle and Papert's interpretation [31] in which bricolage becomes a way of "learning by making". Thus, the outlook is naturally limited and any making will inevitably be of the unselfconscious kind.

Finally, there are a wide range of related and semi-related work from within the maker, DIY, and hacker cultures that we will have to discuss another time. Most notably, perhaps, the Bardzels and Toombs use of adhocism [2] or the repair work studied by Jackson \& Kang [15].

\section{INTERACTION DESIGN AS A BRICOLAGE PRACTICE}

The reasons why we find it interesting to further elaborate on bricolage as an interaction design practice are four. First, it offers a material alternative to conceptual design one that is made to cope with the imperfections of our physical world. Second, it levels the importance of all three formelements of interaction design in its non-hierarchal process of making and thus increasing the likelihood of wellbalanced results. Third, it explicitly builds on cultural references and existing material expressions with results inevitably grounded in something familiar. Thus, the results can be seen as a counterweight to the more hyper-modern kind of design. And fourth, the mythical thinking in combination with the implicit design constrains forces the bricoleur to make new connections and thus possibly open new design spaces.

\section{Making and making do}

In interaction design, and especially the tangible and material practices, we are constantly reminded of the unstableness of the physical world. We are often tempted to dismiss this trait as something to be solved with more sophisticated technology yet to come. Often, that will also be the case. Yet sometime there are interesting connections to be found in these imperfections and instabilities. Bricolage offers a way to exploit those rather than dismiss them. The bricoleur will thoroughly study the events of his treasury - explore them together and separately - in the quest for placing them in a materialized structure. And it is through this that bricolage is able to exploit the imperfections.

We use bricolage in our teaching. In an introductory course on making interactive artifacts our students are given a physical computing kit with cheap and unreliable sensors and actuators and we explicitly tell them not to pretend they are better. Instead, we force the students to find the qualities of the technology as it behaves before them - imperfections and all. We force them to 'articulate' these qualities through a series of inspirational bits [28]. Meaning, they build a series of small interactive constructs that each expresses one or more of the electronics' qualities. These constructs or bits then serve as common experience for the students to go on designing an interactive artifact for a given context. The students are later let loose in the lab with instruction to give body to their electronics. They may use all scrape materials and repurpose all discarded projects they can find. The only requirement is that it all will form a coherent working design in the end. The results may not be high-end designs, and the concepts often not too strong, but the imagination and the cunning put into the details of the solutions almost always astonish us. And it is in this we see a quality of bricolage.

Bricolage is about reflective conversations with the materials [26] and the cultural connotations of "what is at hand' as well as it is about making the actual thing as opposed to a sketch or a prototype [5]. It is an in-situ 
practice of making with no plans but with an objective to create structure of what is happening through a material assembly. Bricolage it thus well suited for design situations that allow an exploratory approach or for the creation of one-offs - like in the case of the everyday designer [34], the design researcher, or possibly even the designer aiming for production if accompanied by reverse engineering. As exemplified above, it can also be used in teaching situations as means for the students to become familiar with the technology and force them to engage in a conversation with the materials and especially the unstable physical world.

\section{Leveling the playing field}

As Vallgårda [32] proposes, interaction design can be seen as a negotiation of forms: the physical form, the temporal form, and the interaction gestalt. In conceptual design practice there are often given precedence to one of these simply by being the starting point and because planning for all three at once is a highly complex task [32]. As bricolage and mythical thinking are both non-hierarchical and in-situ at their core the negotiation of forms will only happen in the making and with an importance of each form determined only from the nature of the project as the events unfold. In essence, the interaction gestalt, the temporal form, and the physical form will all be the result of a coherent process of structuring the events.

In the previous case of the students, for example, the temporal form of the technology was only interesting from an interactive perspective. The qualities of the technology were only discerned from en experiential experience. And while the students often chose one as a starting point for giving it a physical body they went as often back to reconsider both temporal form and the interactive experience as all changed through the addition of new elements. Thus, while we can discuss the complexity of interaction design from the view of other practices $[32 ; 33]$ it is inherently dissolved in a bricolage where there is no planning and all happens in-situ with no predetermined hierarchical order.

Rich cultural references and material expressions

The meticulous attention the bricoleur has to pay to "what is at hand' both in terms of personal experiences, cultural annotations, forms, and material qualities ensures the creation of artifacts that are grounded in what we know. The result may break with both prior functionality and expression but there will always be traces of a cultural grounding. Further, it encourages the combination of cultural references (from those present in the bricoleur's treasury) and it is in this we find the likelihood of designs that exhibits rich and complex expressions. Indeed, given how design of technologies from an engineering practice tends to seek an aesthetics and cultural reference, which favor the hypermodern often liberated from any historic reference in interaction gestalts and materials [cf. 20;23] the inherent grounding in bricolage propose an interesting alternative.
An example of a bricolage, from within the interaction design is a musical cabinet called Ajna [12]. This project clearly draws on a rich mixture of cultural references and material expressions (see Figure 1). The musical cabinet comprises a collection of more or less traditional musical instruments that are mechanically operated and digitally controlled [12]. It is the result of collaboration between two artists trained as a musician and a computer engineer respectively. The project lasted three and a half years and was the result of a combination of tinkering and scavenger hunt [12]. The project was conceived as the artists' need for a way to stand out as artists and is thus highly autobiographical [21]. Indeed, our retrospective study of the artists' practice led us to argue how it can be seen as an example of a bricolage practice [12]

"The physical frame of Ajna consists of a re-purposed old rococo vitrine cabinet made from mahogany and bought on an online auction early on in the process. Within this frame a range of mechanical parts are fitted, including three drums, two cymbals, one marimba-style instrument with 20 wooden bars, one sampler, two maracas, two bells, one murmur machine, and one horn. All these parts are digitally controlled mechanical systems, some previously served the purpose of start engines in cars, one used to be a shoe shining machine and even others are handcrafted structures. The original form factors of the cabinet shape the layout of the musical components. The large drums, for instance, are fitted in what once used to be the main doors of the cabinet, using the space behind for the sound to resonate." [12, p. 3]

The result of the project is an interactive musical cabinet drawing on a "combination of rococo, voodoo and steampunk, Ajna is a fusion of cultural and historical references that may be difficult to decode at first encounter" [12].

In a practice of repurposing and hacking what is already there it seems likely that the aesthetic style will be closer to

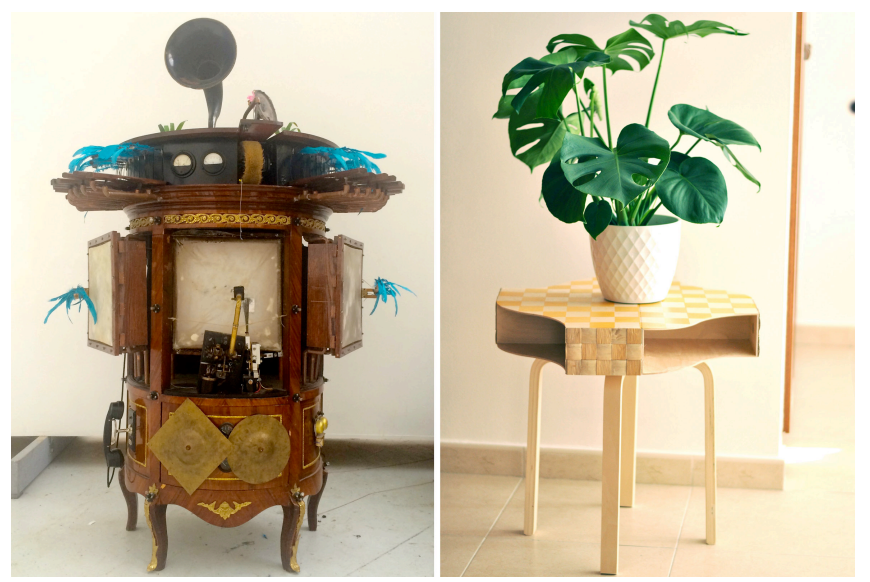

Figure 1. Left: Ajna, a human-sized interactive musical cabinet created by the art- and music collective I Skogen Ibland [12]. Right: An IKEA bricolage coffee table made from KNUFF magazine holders, a FROSTA stool, and a NASUM basket [9] 
Steampunk than modernism. However, the IKEA bricoleurs, for example, provides a different aesthetic (see Figure 1) [24]. In other words, the treasury of the bricoleur, whether it is an IKEA store, old inherited furniture, or the scrape materials from other lab activities, will inevitably set the aesthetic tone of the result.

\section{Making new connections}

Finally, we will make the case that adopting a bricolage practice in interaction design can enable new interpretations of the potential of technology, new forms of use, and new material expressions. We argue thus, that bricolage is not only suited as a design practice but also as a design practice with potential to pivot the field forward - a practice suitable for design research [16].

Bricolage's predisposition for making new connections is twofold. One stems from the restrictions put on the scope of the treasury the other from the even-leveled mythical way of thinking. In both cases, however, the bricoleur must either step into the role of the researcher in order to acknowledge the significance of a new connection in a larger, if not global, context, or it may be a discovery of an on-looker (e.g. an ethnographer).

It is not uncommon in interaction design practice to find ways of putting restrictions on the design practice as means to enforce creative solutions $[13 ; 22]$. Indeed, necessity is the mother of invention. Bricolage can likewise be seen as a set of restrictions on an otherwise open-ended design practice. The restrictions comprise the immediacy of the events that are to be included in the resulting structure - the particular and local treasury, the skill-set of the bricoleur, and the in-situ making.

The mythical way of thinking that accompanies bricolage is about making sense of what is immediately before our senses. The sense making, however, does not have to comply with scientific knowledge or useful solutions. The connections between events, that inevitably will form the resulting structure, just have to be within the scope of the treasure. Like in the case of the touch of a woodpecker's beak and the toothache. Mythical thinking, in other words, is likely to form a more poetic and imaginative set of connections in the bricolage than both functional and scientific thinking would.

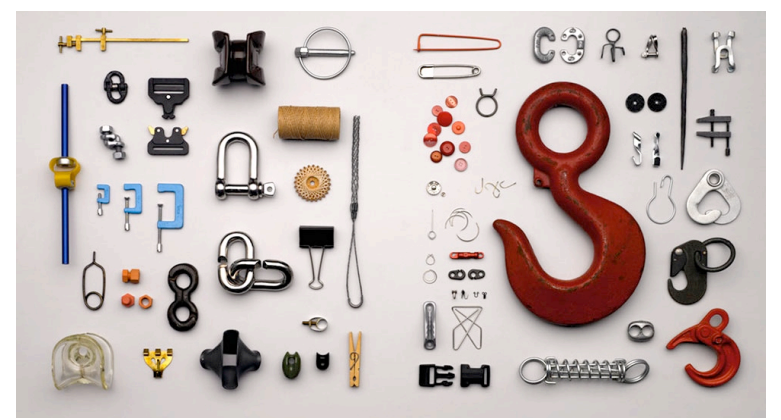

Figure 2. Collection of objects that can hold things together, from the Clivio's No Name Design exhibition in Milan 2014 [6]
As there are not yet many examples of bricolage from within the interaction design literature we have ventured to look at two recent art and design projects which both emphasize new connections in their bricolages.

The first is a peak into an intriguing treasury, and the mind of the Swiss product designer Franco Clivio [7]. Over the years he has collected numerous objects from which he now makes simple yet thought provoking juxtapositions on pictures [7] or in a display cases [6]. For example, his collection of objects that hold things together makes us to reflect on this varied technological landscape (see Figure 2). Indeed, what does it entail to keep two pieces together? How can it be done? What does the material matter? Little had we previously thought of pearl buttons, metal carabineers, and metal paper clips at the same time.

The second, and perhaps more explicitly a bricolage, is the work of the American artist Sarah Sze [29]. Her sculptures make us see ordinary objects, which we normally pay little attention to but often have a bodily experience with (like a plastic water bottle), through a myriad of transitions in complex sculptural universes (see Figure 3). Sze emphasizes transitions in her sculptures and they always seems to be somewhere between construction and deconstruction - a tension which helps or forces the audience to engage. Her sculptures destabilizes the meaning of the singular objects both in the way they are placed in relation to one another but also in how they are placed in the universe of the whole sculpture.

Indeed, the connections made through bricolage are likely to be more poetic and thought provoking than necessarily

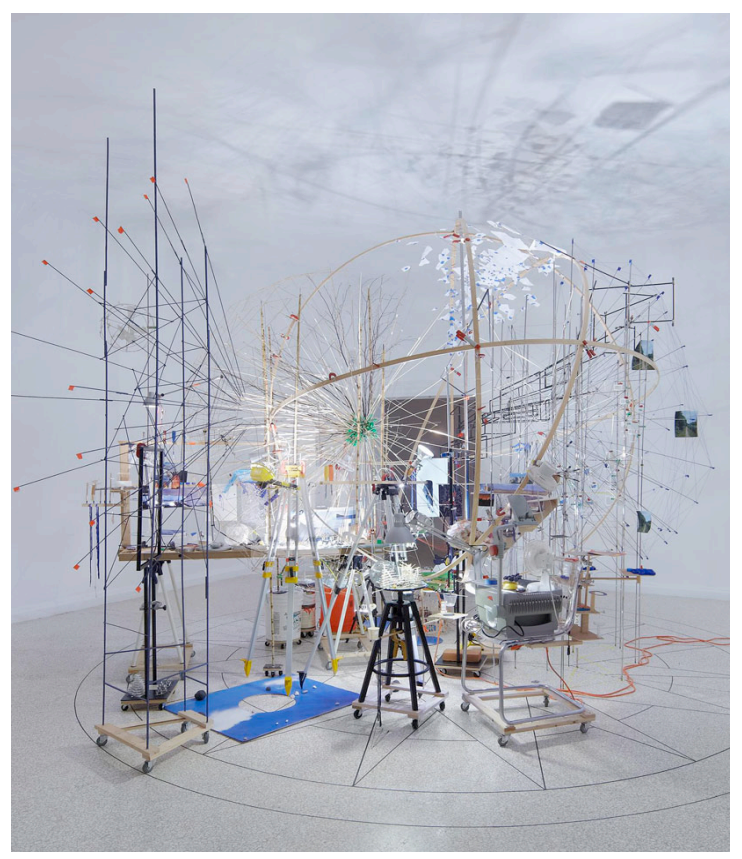

Figure 3. Planetarium by Sarah Sze, 2013 Venice. Materials: wood, steel, plastic, stone, string, fans, overhead projectors, photograph of rock printed on tyvek, mixed media $632.5 \mathrm{x}$ 548.6 x $502.9 \mathrm{~cm}$ [8]. Copyright: Sarah Sze 
useful. However, even the artists of the musical cabinet claimed mechanical inventions in their construction of, for instance, the modified car engine solenoid drumstick structure [12].

\section{CRITIQUE OF A BRICOLAGE PRACTICE}

In a sense bricolage and mythical thinking can be seen as an attempt to romanticize the naïve. However, we would rather propose it as becoming an expert in open-mindedness. Indeed, the bricoleur can hold specialized skills and be knowledgeable in certain fields. However, it is likely that he will encounter tasks for which he has not trained and in such situations he is resourceful with what he has got and already know. Further, with interaction design being as interdisciplinary as it is and the design teams often lack one or another expertise being a bricoleur can actually prove desirable if not explicitly necessary.

Nevertheless, accepting a local outlook and restrictions on the treasury is an almost certain way of obtaining suboptimal solutions. Not seeking and making use of new technological inventions can seem counterintuitive in a field that thrives on technological invention. However, what is globally suboptimal may be good enough if not better locally. As we have argued bricolages may hold other qualities than the functionalistic ones. Their cultural and material grounding, for instance, may render an aesthetics that makes them locally superior. Still, the restricted outlook does produce the risk of conservative solutions with the starting point always being in what is and what used to be, and this even from a cultural and aesthetical perspective.

Further, interaction design is traditionally a practice with a high sensitivity for the future user and her situation. And while the bricoleur will be emphatic and consciously or unconsciously put himself "in the place of the person for whose use it is intended" [17, p. 27] it will demand some sort of experience with the context of the intended use. In other words, the bricolage is highly dependent on the personal experiences of the bricoleur. As Büscher et al. [4] show this could perhaps be remedied by letting the bricolage take place with the people, for which it is intended, in a sort of co-design process. These would then be included in the collection of events for which the bricoleur had to find a structure

Interaction design research has been known to produce many one-offs that are not necessarily reproducible. A bricolage is explicitly so. The musical cabinet, for instance, is not replicable - it is and will be unique. Obviously, in some cases reverse engineering may be applied to open up the bricolage and produce the necessary sketches and optimizations. However, it is more likely that a bricolage practice will tailor to situations where the unique is desired or at least accepted. In design research, bricolage practice enables a posteriori knowledge development through the materialization of a new connection.
Lastly, we are not trained to be limited in our outlook. We more or less do have the world at out feet with the Internet and an abundance of technologies, materials, and tools available for our purchase - often at a relatively low cost. Thus, as Louridas' points out [18], we will almost always be responsible for the extent of our treasury. We will always have to set the limit. In the case of the musical cabinet [12] the limit was defined by an artistic and autobiographical vision as well as limitations on budget and time.

Further, seeing as many interaction designers are trained as engineers adopting a mythical way of thinking may prove difficult and confusing, because it demands that they let go of the global outlook. However, with some practice it may be possible and we believe there is value to be found in designing with the mindset and constraints of bricolage.

\section{CONCLUSION}

Introducing bricolage as an interaction design practice is primary meant as an alternative to the conceptual design. As we have argued it promotes some design qualities, which are specifically attuned to tangible and material computing practices primarily due to its sensibility towards the unstable physical world. Just as the in-situ negotiations of concerns from a non-hierarchical perspective is likely to ensure coherent and well-balanced interactive design artifacts.

Further, the cultural and material grounding, which it promotes, are qualities that we find can have merits in an interaction design practice, perhaps again, primarily in material and tangible interaction. And finally, the in-situ constrains of bricolage and the leveled non-functionalistic structures of mythical thinking seem well suited in a quest for new connections. Thus a bricolage practice may very well be fruitful way of pivoting the field forward.

Indeed, with this paper we have sought to propose bricolage, not as a manifesto, or as something to be followed dogmatically, but as a design practice and a mindset highly suitable for interaction design.

\section{ACKNOWLEDGEMENTS}

This research was partially conducted as part of the Arts and Crafts project at Mobile Life Centre, funded by Vinnova in partnership with Ericsson, Microsoft, Nokia, IKEA, and Stockholm City.

\section{REFERENCES}

1. Alexander, C. Notes on the Synthesis of Form. Harvard University Press. 1964

2. Bardzell, J., Bardzell, S., \& Toombs, A. Now That's Definitely a Proper Hack": Self-made Tools in Hackerspaces. In Proc. CHI '14, Toronto 2014, pp. 473476.

3. Blackwell, A. F. Gender in Domestic Programming: from Bricolage to Séances d'Essayage. In Proc. 
CHI'2006 Workshop on End User Software Engineering, 2006, pp. 1-4.

4. Büscher, M., Gill, S., Mogensen, P., \& Shapiro, D. Landscapes of Practice: Bricolage as a Method for Situated Design. Computer Supported Cooperative Work. 10, (2001) 1-28.

5. Buxton, B. Sketching User Experiences: Getting the Design Right and the Right Design. Morgan Kaufmann. San Francisco. 2007

6. Clivio, F. No Name Design. (2014).

7. Clivio, F., Hansen, H., \& Mendell, P. Hidden forms. Skira. Milano. 2014

8. Designboom. Sarah Sze represents the US at venice art biennale 2013. http://www.designboom.com/art/sarahsze-represents-the-us-at-venice-art-biennale-2013/ (Retrieved: August 1 2014)

9. Emerjadesign. Coffee Table. http://www.ikeahackers.net/2014/06/new-version-ofthe-coffee-table-with-knuff-magazine-files.html (Retrieved: July 30 2014)

10. Fallman, D. Design-oriented Human Computer Interaction. In Proc. CHI'03, Fort Lauderdale April 5102003 , pp. 225-232.

11. Fernaeus, Y. Let's Make a Digital Patchwork: Designing for Children's Creative Play with Programming Materials. PhD Stockholm University. Stockholm. 2007

12. Fernaeus, Y. and Vallgårda, A. Ajna: negotiating forms in the making of a musical cabinet. In Proc. DIS'14, Vancouver June 21 - 25 2014, pp. 915-924.

13. Gaver, W. W., Beaver, J., \& Benford, S. Ambiguity as a Resource for Design. In Proc. Ambiguity as a Resource for Design, Fort Lauderdale, FL, USA 2003, pp. 233240.

14. Hazlewood, W. R., Dalton, N., Marshall, P., Rogers, Y., \& Hertrich, S. Bricolage and consultation: addressing new design challenges when building large-scale installations. In Proc. DIS'10, Aarhus 16-20 August 2010, pp. 380-389.

15. Jackson, S. J. and Kang, L. Breakdown, Obsolescence and Reuse: HCI and the Art of Repair. In Proc. CHI '14, Toronto 2014, pp. 449-458.

16. Koskinen, I., Zimmerman, J., Binder, T., Redstrom, J., \& Wensveen, S. Design Research through Practice: From the Lab, Field, and Showroom. Elsevier. Waltham, USA. 2011

17. Lévi-Strauss, C. The Savage Mind. University of Chicago Press. Chicago. 1966

18. Louridas, P. Design as Bricolage: Anthropology Meets Design Thinking. Design Studies. 20, 6. (1999) 517535 .
19. Manzini, E. The Material of Invention: Materials and Design. MIT Press. Cambridge, USA. 1989

20. Microsoft. Future Vision. http://www.microsoft.com/office/vision/ (Retrieved: July 30 2014)

21. Neustaedter, C. and Sengers, P. Autobiographical design in HCI research: designing and learning through use-it-yourself. In Proc. DIS 2012, Newcastle Upon Tyne, UK 2012, pp. 514-523.

22. Pierce, J. and Paulos, E. Counterfunctional things: exploring possibilities in designing digital limitations. In Proc. DIS'14, 2014, pp. 375-384.

23. Rogers, Y. Moving on from Weiser's Vision of Calm Computing: Engaging UbiComp Experiences. In Proc. UbiComp'06, Irvine, CA 2006, pp. 404-421.

24. Rosner, D. and Bean, J. Learning from IKEA hacking: I'm not one to decoupage a tabletop and call it a day. In Proc. CHI'09, 2009, pp. 419-422.

25. Ryokai, K., Lee, M. J., \& Breitbart, J. M. Children's storytelling and programming with robotic characters. In Proc. C\&C'09, Berkeley 2009, pp. 19-28.

26. Schön, D. A. The Reflective Practitioner: How Professionals Think in Action. Basic Books. New York. 1983

27. Stolterman, E. and Wiberg, M. Concept-Driven Interaction Design Research. Human-Computer Interaction. 25, 2. (2010) 95-118.

28. Sundström, P., Taylor, A. S., Grufberg, K., Wirström, N., \& Belenguer, J. S. Inspirational Bits: Towards a Shared Understanding of the Digital Material. In Proc. CHI'11, Vancouver 2011, pp. 1561-1570.

29. Sze, S. The meaning between things. http://channel.louisiana.dk/video/sarah-sze-meaningbetween-things (Retrieved: August 1 2014)

30. Tanenbaum, J., Tanenbaum, K., \& Wakkary, R. Steampunk as Design Fiction. In Proc. CHI'12, Austin May 2012, pp. 1583-1592.

31. Turkle, S. and Papert, S. Epistemological pluralism: Styles and voices within the computer culture. Signs: Journal of Women in Culture and Society. 16, 1. (1990) 128-157.

32. Vallgårda, A. Giving form to computational things Developing a practice of interaction design. Personal Ubiquitous Computing. 18, 3. (2014) 577-592.

33. Wakkary, R. Framing complexity, design and experience: a reflective analysis. Digital Creativity. 16, 2. (2005) 65-78.

34. Wakkary, R. and Maestri, L. Aspects of everyday design: Resourcefulness, adaptation, and emergence. International Journal of Human Computer Interaction. 24, 5. (2008) 478-491. 